Article

\title{
Foodways, Campervans and the Terms of Mobility: Transnational Belonging, Home, and Heritage in the Narrative of "Sud Italia"
}

\author{
Georgia Wall \\ School of Modern Languages and Cultures, University of Warwick, Coventry CV4 7AL, UK; \\ g.wall@warwick.ac.uk; Tel. +44-(0)24-7652-3462 \\ Academic Editor: Francesca Muccini \\ Received: 16 February 2016; Accepted: 11 April 2016; Published: 21 April 2016
}

\begin{abstract}
International popular culture continues to remediate and perpetuate the link between food and ideas of Italian identity. A range of analytical approaches have become concerned with food and drink in Italian culture: the importance of food industries in patterns of Italian migration and Italy's economy, the recurrence of the Mediterranean diet in public health debates, the emotive value attached to foodways, and their role in constructing subjectivity are all recognized as fertile terrain for research. Nevertheless, a lack of audience-reception research on the social and cultural uses of both food and food-related media has been identified. Responding to this inviting opening, the following article is based on data collated between October 2014 and January 2016 as part of the ongoing "Transnationalizing Modern Languages" project. Focusing on London as a particular axis of both contemporary and historic Italian migration to England and the UK, my research utilizes selected small-medium food enterprises in the UK capital, and the personal narratives of migration they form part of, to reflect simultaneously upon the contemporary appeal of foodways read as Italian in Britain and the practical implications of meanings ascribed to foodways by subjects identifying as Italian. Positing the intersection between public and private represented in these food narratives as one of the most productive sites for reflection upon more general social development and experience, I offer a critical reading of "Sud Italia", a mobile pizzeria in which the contradictory dynamics of subjectivity/objectivity and mobility/fixity are symbolised. Drawing on participatory ethnography, the article seeks to contribute further understanding to the multifaceted concepts of "belonging", "home" and "heritage" by grounding their relevance in practical, day-to-day realities.
\end{abstract}

Keywords: Italy; foodways; mobility; belonging; home; heritage; transnational; subjectivity

\section{Introduction}

Ice-cream carts, fish and chip shops, cafés; then, after World War II, the introduction of pizzerie, trattorie, and coffee bars: the economic structures of Italian migration to the UK are historically underpinned by food [1]. From the celebration of Sophia Loren's declaration "everything you see, boys, is down to Italian pasta" ("tutto quello che vedete, boys, lo devo alla pasta italiana"), to the gastronomically cathartic Italy of Elizabeth Gilbert's best-selling novel Eat, Pray, Love (2006), international popular culture continues to remediate and perpetuate the link between food and ideas of Italian identity. Accordingly, a range of analytical approaches have become concerned with food and drink in Italian culture: the importance of food industries in patterns of Italian migration and Italy's economy, the recurrence of the Mediterranean diet in public health debates, the emotive value attached to foodways, and their role in constructing subjectivity are all recognized as fertile terrain for research. Alongside this more recent general "explosion" of academic interest in food [2], the study of quotidian practice has established an ethical claim in historiographies which place significance on the more mundane 
aspects of life as capable of revealing angles obscured by official histories tied to dominant point of view [3]. "Foodways", or the entirety of "behaviours and beliefs surrounding the production, distribution and consumption of food" $([4], \text { p. } 2)^{1}$, represent a current focal point of scholarly attention.

Nevertheless, a lack of audience-reception research on the social and cultural uses of both food and food-related media has been identified ([6], pp. 27-38). Responding to this inviting opening, the present article is based on data collated via participatory ethnography, including semi-structured participant interviews, between October 2014 and January 2016 as part of the ongoing "Transnationalizing Modern Languages" project ("TML"). TML is one of three large grants funded by the UK Arts and Humanities Research Council under the 'Translating Cultures' theme, which promotes investigation of cultural exchange between communities and individuals across time and space via the study of translation in its broadest sense. Involving researches at the Universities of Bristol, Cardiff, Leeds, Queen Mary, St. Andrew's, and Warwick, together with several international academic and community partners, TML focuses on modern Italy and the experiences of mobility that are embedded in its recent history to critically reflect upon instances of linguistic and cultural translation [7]. Ethical consent was obtained from all participants prior to interview and unpublished interview transcripts are available upon request. Accepting food and eating as "central to our subjectivity, or sense of self, and our experience of embodiment, or the ways that we live in and through our bodies, which itself is inextricably linked with subjectivity" ([8], p. 1), I employ food and foodways to profile and examine Italianità ("Italianness", or "being Italian") in migration. Focusing on London as a particular axis of contemporary and historic Italian migration to England and the UK, a traditional point of arrival for Italian migrants in the nineteenth century, and the "symbol" of the new flow of migration from Italy observed in more recent decades ([9], p. 155), my research centres around small-medium food enterprises in the UK capital. The personal narratives of migration that form part of the fabric of these sites are explored via ethnography, understood as

not a specific data collection technique but rather a multiple technique approach, by which the ethnographer can adapt and draw upon a mix of methods appropriate to a situation. Research and data collection takes the form of diverse experiences, workshops, encounters, relationships, observations as opposed to closely structured interviews as it is only as the conversations and interviews progress that the next question emerges ([10], p. 5).

A brief note on my own position in terms of data collection: I am not Italian. I moved to London for the first time in 2013, after living in Italy for five years. The Italian I speak is heavily inflected with an intonation and idioms identified as "Southern", and it should be highlighted as contributing to a specific dynamic in my ethnography: the self-conscious (at times awkward, explanatory, or perhaps proud) act of recounting an experience to an "outsider" researcher in interview is set against the more spontaneous interaction typical of people who unexpectedly find themselves sharing common referents, such as highly specific local knowledge and dialectal phrasing. This is not to claim "insider" status, nor to presume the value of the position of cultural "insider" over a more detached observer for research purposes, but merely to recognise the particular set of circumstances in which the stories I am collecting unfold. These narratives are used in my research to reflect simultaneously upon the contemporary appeal of foodways read as Italian in Britain and the practical implications of meanings ascribed to foodways by subjects identifying as Italian. Given that I have found legal classifications of national status often bear little relevance ([11], p. 186) or directly obscure the identity processes that I am interested in, this definition is deliberately broad, and includes both statements of citizenship as well as those of heritage articulated by descendants of Italian migrants.

1 I use Carole Counihan's definition. As shorthand for a holistic system of food conceptualization, procurement, preservation, preparation and consumption, the term is usually attributed to Jay Anderson-see [5] - though it is likely to originate in American anthropology of the 1940s (John William Bennet in 1941, and slightly later, in 1948, John Honigman used the term to refer to general food habits of a population). 
This article concentrates on one of the enterprises collaborating with the study, "Sud Italia". A "mobile" pizzeria at London's Old Spitalfields Market, the implicit mobility and contradiction represented by this now static vehicle and the narratives arising from it illustrate particularly well the themes raised recurrently by a range of participants. I begin with a theoretical distinction of the notion of belonging from that of home, analysing Sud Italia as a symbolic nexus of tensions of subjectivity/objectivity and mobility/fixity. Defining "home" as the original source of a collective frame of reference, the article then moves to consider the implications of a detachment from home from the point of view of Silvestro, the founder and owner of Sud Italia. The final section of the article uses insights from this dialogue to reflect upon a question whose relevance extends beyond these specific circumstances: how can heritage relate to a sense of belonging?

Rodney Harrison identifies a contradiction in the aims of global heritage in that world organizations such as UNESCO "might impose a universalizing trend on local diversity" even as they "step in to protect diversity, particularly from strongly homogenizing tendencies of the nation-state" ([12], p. 155). Drawing upon Silvestro's reflections on world heritage and UNESCO during interview, Sud Italia as a case study responds to Harrison's interest in "the ways in which the tensions between these two aims of global heritage management are played out in the real world" ([12], p. 155).

It thus contributes a further example, from a UK context, to the stimulating range of analyses employing foodways as a means of grounding the relevance of broad, multifaceted concepts in practical realities. Abel Duarte Alonso, for instance, has shown through the positioning of the Tannat wine grape in Uruguay how cultural traditions "can be maintained and reinforced through iconic [food or beverage] products representing the character of the region or country" ([13], p. 1). Anne Allison uses her experience of the obento lunch box in Japanese nursery schools to creatively rethink issues of female agency and state ideologies of power [14], and Meredith E. Abarca inspiringly problematizes the claim of "authenticity" in food production via her participation in "culinary chats" ("charlas culinarias") [15]. My reasoning here aligns with the approaches exemplified in these investigations, as well as Donna R. Gabaccia and Loretta Baldassar's Intimacy and Italian Migration [16], to call for the development of interventions which can shed light on how individual experience is not only informed by, but also works to inform, more general social concerns.

\section{Belonging: "to Be Rightly Placed in a Specific Position"?}

Twenty years ago, in "The World on a Plate", Ian Cook and Philip Crang called for a reconceptualization of approaches to the material geographies of culinary culture that worked with processes of commodity fetishism; rather than search for "authentic" realities, they reasoned, a more productive critical intervention ought to consider the meanings and use of food placings as locally-constructed, situationally-specific identity projects [17]. Abarca's aforementioned work offers precisely that, arguing how "authenticity" as a form of essentialization imposed both by cultural outsiders and those within the culture "boxes in certain ethnic others" ([15], p. 19). Looking to tease out the implications of this mechanism in different contexts, I return to Cook and Crang's "global post-modern" space in which the "homogenizing impacts" of transnational capitalism are observed simultaneously alongside the "staging and (re)construction of cultural difference": London ([17], p. 133).

Today, descriptions of London's Spitalfields Market in TimeOut as a cosmopolitan trading hub echo the magazine's earlier "boast" of a metropolitan melting-pot which provided the point of departure for Cook and Crang's original study:

Redevelopment has seen this East End stalwart combine the refurbished 1887 covered market with a modern shopping precinct. Around the edge, enthusiastic stallholders sell grub from just about every corner of the world [18]. 
With the feel of a mall-with-market, it is now neatly cleaved in two by a slick of chain restaurants [...]. On one side lies an arcade of smart shops and eateries bordered with orderly market stalls (Spitalfields), and on the other, a cross section of stalls crammed into Old Spitalfields [19].

The historic wholesale fruit and vegetable market associated with the site moved to Leyton in 1991, and the redevelopment of the Spitalfields area over the turn of the last century has been cited as further contributing to the controversial "gentrification" of an area of London often framed in terms of poverty and deprivation, and defiantly celebrative of its interculturality [20]. Underneath the Victorian trussed roof of Old Spitalfields, the smell of frying garlic mingles with battered fish, stacks of cinnamon-dusted baklava face blended drinks in pale pastels, buttery cheese is scraped and spread as hissing beanshoots are flipped in giant woks; on communal tables, couples, families, businessmen, and tourists stretch their mouths round burgers and banh mi, and idly dip chips in ketchup and dim-sum in soy sauce. Near the north-east entrance to the market, a customised 1974 Citroën $\mathrm{H}$ van with a wood-fire pizza oven (and sky-blue finish, to match the football strip of Naples) presents itself: "Sud Italia-Pizza Napoletana".

A collaborator from the start of my research, Aldo, a 37-year-old Italian of Neapolitan heritage who has lived in London for 4 years, first suggested a visit to Sud Italia for "authentic" Neapolitan pizza in London. Without going into the issue of authenticity per se, it appears useful to point out how Sud Italia's success corresponds to Arjun Appadurai's attempts to deconstruct the puzzle of the value of authenticity:

"Authenticity is typically not the concern of native participants in a culinary tradition, except when they (and the food) are far from home. It generally arises in the contexts of export, tourism gourmandise, and exoticism. The concern with authenticity indicates some sort of doubt, and this sort of doubt is rarely part of the discourse of an undisturbed culinary tradition. It is the problem of the outsider [...]. Quality is typically the insider's concern, authenticity that of the culinary tourist" ([21], p. 25).

Sud Italia is accordingly frequented on the one hand by a broad cross-section of Italian migrants to London who laud the high quality product, Neapolitan-style pizza. Many participants have emphasized that "a good pizza" is not something they miss from Italy, and one used Sud Italia as a benchmark for excellence, commenting that the pizzeria in his family town in Italy was "almost as good". On the other hand, comments such as "Trust me, mate, this is a real Italian pizza", and the like, exchanged between suited businessmen queueing for pizza in their lunch break, point to the ways in which the capacity to recognize "authenticity" functions as a marker of social distinction amongst cultural outsiders. It is "one form of demonstrating cultural capital", as Tammi Jonas acerbically suggests, "usually more readily available to those with the economic capital to have travelled to the countries in question" ([22], p. 130).

In a broader discussion of ideas of home stemming from interviewee accounts of transnational kin relationships, Aldo provided a useful lens from which we might contemplate Sud Italia:

If I had to express what it feels like to be part of a family-the image of a family-I think of holidays in the campervan. When we went on holiday-all six of us-in the campervan, that sums up to me everything that's important about family. Everyone had their own thing, you know: Valentina and Daniela looked after us, invented hilarious games; my Mum cooked, obviously, copious amounts of pasta [...]. I remember I felt important at that time as it was then my Mum started to comment that I was good at fixing things. Everyone had their role-because you know, when you're camping, you need that [...] and that was us, we were the Carola family.

Extracting from this image of a family the association of a sense of belonging with each member having "their role", I invite the reader to reflect upon how belonging might be expressed beyond 
emotional attachments in mundane realities. Traditionally, belonging has often been conceived in terms of affect; Abraham Maslow's human motivation theory proposed belonging as "a hunger" for affectionate relationship with people in general [23], and David McMillan and David Chavis recognised it as part of acceptance by and in a community [24]. Rather than interpret this type of connectivity in an emotive sense, interest here lies in practically relating the idea of belonging to the claiming and fulfilment of a specific role. In its most concise form, the Oxford Dictionary of English defines belonging as being "rightly placed in a specified position". My first approach to Sud Italia builds upon this simple point of departure, together with Aldo's analogy, to interrogate emplacement and fixity in relation to Sud Italia and consider how the "performance" of identity works to fix bodies. Recognising identity as an ongoing process rather than an essentialist boundary, this article upholds Judith Butler's original arguments, but with a more fluid definition of performance than that employed in her discussion [25]. Specifically, considering how movement between physical contexts (in this case, from Italy to England) inflects upon the creation and interpretation of meaning, I reject Butler's distinction between "performance" and "performativity". This is in line with Tim Edensor's observation that

apparently self-reflexive performances may become unreflexive "second nature" to the habituated actor, and unfamiliar surroundings may provoke acute self-awareness of iterative performances where none had previously been experienced (my emphasis) ([26], p. 71).

Symbolically representing both movement and fixity as a stationary van, Sud Italia provides a particularly apt case study to shed further light on how being fixed as Italian, or deploying an objectified form of Italianità as an "asset", in this case, may—as Terry Lovell highlights—simultaneously curtail and enable existence as a capital-accumulating subject ([27], pp. 37-38). In the extract below, Silvestro Morlando, the founder and owner of Sud Italia, has been asked whether he would like to return to Italy, and voices the significance of the location of his business in its achievements:

When I go to Naples, I literally shake and want to cry. That city gives me a wonderful feeling. It's just that [...] here there's something else. Here, if you're thinking of your own future, in the sense of a family, having some security-here you can. Yes, the cost of living's really high, but I open up in the evening and in the morning, I start making pizzas, and I start making money. In Italy, if Monday, Tuesday, Wednesday, Thursday-[you tried to do the same thing] you'd starve to death, practically. You could be selling the best pizza in the world [...]. I think maybe in Rome or Milan you could make money. If I tried something like this is Rome or Milan it could work. But if I've got to move [away from my home town] anyway, I'd rather stay in London.

Product quality aside, Silvestro's statement marks Sud Italia's market success as related to a specific positioning: one that is physically detached from an identified point of origin, allowing cultural "otherness" to become a characteristic feature of the business. Responding flexibly to consumer interest in rustic, rural pasts, Silvestro and his two colleagues have adopted Sicilian-style flat caps and mock braces as an informal working uniform. "My first idea was to set up a business selling arrosticini [salted lamb skewers, a speciality of the Abruzzo region]", he told me. But after various jobs in different catering establishments, and developing a greater mastery of the language, he saw pizza as a way to capitalize on a natural asset: his Italianità: "Yes, the owners are English", he says of a successful competitor, "but that's not what you see when you go in there; all the waiters are Italian, all the pizzaioli are Italian, and that's the secret, people trust they're getting the real deal." In postulating the viability of the business model in Rome or Milan, he indirectly acknowledges further the value in being objectified or "othered" as culturally "different"—in this case, as "Southern Italian". He also reiterates the long-standing internal typecasting of an industrially rich North of Italy and a lagging "Southern" economy, a point I return to later. Here, we might usefully identify Sud Italia as a "transnational object", in Laura Marks" terms; that is, a highly visible, essentialized Italianità that is animated "in cultural 
translation and transcultural movement" ([28], p. 78). It is the movement from Italy to Britain which enables Sud Italia to be fixed as "Italian". And yet, it is precisely through the visibility of Italianità in Britain, through being placed in a specified position-belonging as Italian-that Silvestro, with Sud Italia, acquires a higher level of socio-economic mobility. In short, it is mobility (the move from Italy to England) that promotes fixed typecasting as "Italian", and by being fixed as Italian, he achieves economic mobility: owning Sud Italia is allowing Silvestro to significantly improve his financial lot, with further vans and a restaurant envisaged, and the secured interest of external investors.

This pronounced example of the contradictions in binaries of subjectivity/objectivity and movement/fixity provides an illustration of how "belonging" can theoretically be considered quite separately from discourses of "home", and is an interesting point to bear on Paul Jones and Michal Kryzyzanowski's meditations on belonging in relation to notions of migration and identity. Mapping the mechanisms by which a collective identity, composed of multiple and seemingly conflicting attachments, interact with a personal sense of identity, "belonging is to some extent based on an exclusion of the other", assert Jones and Kryzyzanowski; though, "one's belonging can be made up of a combination of elected attachments that sometimes do not need validation or endorsement by the "in-group"' ([29], p. 47). What of Silvestro's case, where, we might suggest, rather than group belonging being based on the exclusion of an "other", it is enabled by being positioned on a shifting scale as the other? Neapolitan in the South, then-Silvestro surmises—the "Southern Italian" in Rome or Milan, and "Italian" for non-Italians London, Silvestro's positioning may be considered in terms of "footing", or "the alignment we take up to ourselves and others present" ([30], p. 128). As indications that "a projected self is somehow at issue" ([30], p. 127) such shifts in footing indicate the mobilization of different scales of identities to secure emplacement in different contexts. This allows Silvestro to carve out a professional niche, but how is this played out in social terms? Put more simply: how does belonging as claiming a place relate to feeling at "home"?

\section{Distinguishing Belonging from "Home" as the Original Shared Frame of Reference}

Scholars across disciplines have traced and problematized notions of "home" variously as a gendered space, as a sentimentalized imaginary of belonging, as a site of conflict [31 $]^{2}$. Here, I borrow David Morley's most succinct classification as a literal point of departure: home is "a place to start from" ([31], p. 1). Though this may be identified as a physical site-a house, a street, a town, a region-or associated with specific people, I want to suggest that emotive definitions of home relate primarily to the recognition of a space from which our way of interpreting the world is derived; the site of a collective frame of reference. "Make yourself at home" or "fai come se fosse casa tua" are, in base form, invitations to share or even set behavioural norm: to be "at home" is to assume the capacity to be interpreted, and to interpret others according to mutually familiar terms.

To illustrate this further, let us return momentarily to Aldo's campervan as a symbolic representation of a sense of belonging, and his comment that "I remember I felt important at that time as it was then my Mum started to comment that I was good at fixing things". Whilst perspectives from the social sciences might read "in-group" validation or recognition in this statement, what I would like to draw attention to here is the explicit acknowledgement of the significance of a shared reference frame in the conferral of meaning upon individual positioning. Individuals acquire the ability to "interpret their own experience through the "lens' of a (perceived) common frame of reference" when they form part of a collective, affirm Jones and Kryzyzanowski ([29], p. 50). "Home", then, for the purposes of this article is the primary location of this imagined frame: the place to refer back to, the point from which individual experience can be decoded, in itself a shifting point across various social,

2 Morley provides a comprehensive analysis of the evolution of the concept of home, particularly in relation to notions of mobility. For an exploration of the value, significance and location of home in narratives associated with contemporary Italy and migration, see also the dedicated chapter in Jennifer Burns, Migrant Imaginaries: Figures in Italian Migration Literature [32]. 
spatial and temporal contexts. This is not to suggest that such a frame may not also be rooted in a physical locality, but merely to acknowledge that a person's idea of home will change not only over the course of a life, but from one conversation to another, depending on who the speaker addresses, the context in which the conversation takes place, and a myriad of other factors.

Bringing back questions of affect, connectedness and common values, and working on the premise that home can be understood as an individual's primary source of a collective frame of reference, it is clear that transnational mobility is a process which can translate the theoretical distinction between home and belonging into a practical reality. Moving from one environment to another generates exposure to alternative positions and forms of emplacement and therefore engenders new experiences of belonging. We might posit that a disjunction of the experience of "belonging" (being rightly placed in a specified position) from that of "home", as the original source of an (imagined) collective frame of reference, is an inherent element in these mobility routes. According to this process, "home" emerges for Silvestro in our conversations as Italy.

In more informal discussion after interview, when Silvestro asked me if and how I had been able to develop social networks in the city, he invoked archetypal images of a close, "traditional" Italian family life: "Do you, for example, eat with your family on Sundays?" We spoke at length about relationships with relatives, in particular grandparents, as experienced in Italy, and observed in London. Despite the fact Silvestro did not foresee returning to Italy (as he reiterated, "If I tried something like this is Rome or Milan it could work. But if I've got to move [away from my home town] anyway, I'd rather stay in London"), he voiced concerns over a lack of emotional/social attachments with "Londinesi", a sense of detachment not only from traditional family life but also in general social experience. Recounting exchanges between neighbours, he returned to what he described as "Italian" habits, contrasting the courtesy and correctness of his neighbour with the sociality of apartment blocks he had lived in, in Italy: "perhaps it's us that are too invasive, but people in the block (...) know each other. Oh, hi, how are you? Come and have a coffee!"

Equally significantly, home-in-Italy is alluded to as a reference system of value, a means of measuring self-worth. Another participant doubted Silvestro's assertion that he would "starve to death" should he attempt to run a similar business in Italy, arguing that the quality of the product stood an excellent chance, and that Sud Italia would find a ready market in "a nation of people who will always find a few coins for a good pizza [like that]". Silvestro denies the economic viability of the model in the current climate, but when recounting previous work experience of both himself and earlier generations of his family, he added suggestively that "in Italy, you're always that poor devil ('poveraccio') that does the markets". So whilst London for Silvestro, as in many of the narratives of my study, is identified here as the environment which enables him to achieve his vision of self-fulfilment, his comment places "home" - as the means of measuring this fulfilment—elsewhere. That is: simply by merit of its London location, Silvestro implies, Sud Italia is of greater social prestige from an "Italian" perspective than it would be if it were based in Italy. As the site of a collective reference system of values and social norms, therefore, "home" appears remains located in Italy.

For those individuals, such as financial and legal specialists, who are attracted to London as a commercial hub and spend on average only 3-5 years in the capital ([33], pp. 1-2), and who tend to socialise with similarly mobile professionals ([9], p. 161), a strong attachment to, and selective maintenance of traditional frames of reference is to be anticipated. However, based on my research, a comparable dichotomy of belonging/home is legible even in the cases of individuals who do not aspire to return to Italy, who expressed satisfaction with their lives in London and envisaged their future in the city, as they concurrently doubted whether the city could represent "home" for them. This is in line with existing reports of the dynamics of wider contemporary European migration to London: Russell King et al. identify lack of contact with English people as a feature of the experience of migration from Germany to the capital ([34], p.15), and Giuseppe Scotto, in his comparative ethnography of contemporary and historic Italian migration to London, finds that the "new" first generation of Italian migrants-bar those in a relationship with an English partner-reported it easier to create close 
friendships with other Italians, or of other nationalities, rather than English people ([9], p. 160). Scotto attributes this to a "preference for spending time and/networking with people with whom they have something in common, for example with other 'eurostars', with whom they share the experience of migration to a multi-ethnic metropolis like London" ([9], p. 161). In the interviews I have conducted, however, this was not expressed in terms of preference, but as a source of frustration, and on occasion, self-doubt: "is it really possible that after over four years here, day in day out, working with English people, there's no-one I feel I can call on a whim and organise a chat with; a coffee, a beer, a match of five-a-side football? I think perhaps I left it too late to try moving here, probably the guys in their twenties don't have this problem." Age, as in this example, and a sense of linguistic incompetence were frequently cited as potential motives for perceived alienation and detachment from English social networks. A recurring image was that of English people "huddled in pubs" and distaste, or explicit disgust, was articulated towards a drinking culture identified by many as endemic in the city. It is important to point out here that often, for those participants originating from smaller Italian towns and villages, settling in London represented their first sustained encounter with a metropolitan environment. The impressions from this specific context would therefore merit further scrutiny from a wider perspective, incorporating the discourses social dispersion that often recur in narratives of migration from rural areas to more densely populated urban centres, even within national borders. Here, my argument is merely that a lack of development of new collective frames of reference marked by professed inability to create social networks with non-Italians in London must be related the maintenance of home elsewhere, and that these processes require greater attention.

Acknowledging the mutual recourse to stereotypes-both of England, and of Italy-Silvestro's comments nevertheless highlight the power of definitions of home as, in Bo Stråth's words, "an imaginative project in which culture, folklore, music and art enjoy the luxury of certainty" ([35], p. 26). This of course is not remarkable in itself-as Loretta Baldassar states, "notions about close family ties have come to be associated with italianità at home and abroad, perhaps most particularly in the migrant imaginary" ([11], p. 173). But rather than simply accept these images, might we not look to shed light on the processes which enable and promote these associations? Silvestro's story is but one example of the trope that sees emigration as a "catalyst" for self-reflection, for "the creation and for the questioning of images and self-images" ([35], p. 34). Given the importance of migration both in Italy's history and the contemporary period-that is both immigration and emigration, within the national borders and abroad-examining the dynamics and effects of mobility for specific individuals in precise contexts raises issues that can offset and inform a wider portrait of Italy and italianità.

So, if home, as the primary shared frame of reference, is located in a different context to that of belonging, we ought to pay further attention not only to how this disjunction prompts individual reconceptualizations of Italy as home, but to what extent wider collective identifications; those upheld within in Italy, those of migrant Italians and more general external readings of Italy can be seen as products of this process. Of course, I am not suggesting that all experiences of migration involve a sustained detachment of belonging from home: in-group validation and support of individual emplacement and positioning_-of belonging-will enable the development and maintenance of new, and alternative, shared frames of reference: new homes. But both the creation of new homes and reference back to homes elsewhere seem equally likely to promote a more reflective consideration of that which was originally uncritically identified as "home". Baldassar suggests that absence of attachment to Italy as a physical place "does not impede one from sharing particular notions about family and caregiving, and defining these as Italian" ([11], p. 178). Could we go further, and posit that multiple physical detachments from Italy (multiple individual belongings in a different place, which may or may not in time replace the "original" home), as represented by the migration processes which form part of Italy's history and contemporary reality, play a key role in the creation of collective images of italianità? And how can we go about this? 


\section{Heritage: The Public Articulation of Private Affects}

In seeking to integrate these personal narratives with wider social patterns, one productive approach can be mapped from the points of encounter between the everyday realities of specific individuals and institutional discourse. Here, I argue that the concept of "heritage" can provide an incisive vision of the interaction between the subjective negotiation of lived mobility, and the creative "tactics", as Michel de Certeau describes, that emerge from it, with institutional "strategies" [36] and the broader, more elusive yet highly relevant questions of morality, authority and insecurity that this ambiguous term invokes. On this point, it has been established that the significance of the notion of heritage lies not in its analytical precision, but in its psychological resonance. Graeme Davison explains:

It hinted at a treasury of deep-buried, but indefinite, values. It invoked a lofty sense of obligation to one's ancestors and descendants. And it secured the high ground of principle for the conservationists in their perennial battle against the improvers, developers and demolishers. Heritage - what we value in the past-is defined largely in terms of what we value or repudiate in the present or fear in the future ([37], p. 33).

We thus understand heritage as a mediator, a means of fashioning out of the past that which is contemporarily desired for the future; it exists solely, in Rodney Harrison's terms, "through the reading which it is given by communities and human societies in the present" ([38], p. 3).

Heritage, nevertheless, in all its ideological vagueness, is claimed in precise practices and material forms, and heritage discourse concerning Italy, italianità, and foodways identified as Italian promises insight in its abundance. An important example is the celebrated inscription of the Mediterranean diet on the UNESCO Representative List of the Intangible Cultural Heritage of Humanity in 2013 which highlights the intersection between public and private, between institutional and familial, and between quotidian and remarkable that is encased within contemporary interpretations of heritage. Foregrounding social exchange and communication as key "elements" of the Mediterranean diet, there is a particular emphasis on convivial sites and intergenerational transmission:

Women play an important role in transmitting knowledge of the Mediterranean diet: they safeguard its techniques, respect seasonal rhythms and festive events, and transmit the values of the element to new generations. Markets also play a key role as spaces for cultivating and transmitting the Mediterranean diet during the daily practice of exchange, agreement and mutual respect [39].

The list entry, shared between Cyprus, Croatia, Spain, Greece, Italy, Morocco and Portugal thus suggestively points to a desire to preserve and celebrate models of sociality, as well as feminine domesticity and matriarchal systems of communication. Heritage is, in this sense, the public articulation of private affects: a process through which collective insecurity-anxiety towards perceived contemporary threats to value-imbued resources-may be addressed and channelled into a binding commonality. Harrison summarizes:

An attachment to the past encourages people to keep mementos, and can begin to create resistance to change at a larger scale, as well as fostering the notion of heritage as a shared and collective thing that binds society (or perhaps more accurately, parts of a society) together ([38], p. 2).

Lynn Meskell notes how the language of heritage has become dominant in American (and I would add, in European) culture:

Whilst seemingly uncontroversial, "heritage" occupies a positive and culturally elevated position within many cultures, yet we should recognize that not all individuals, groups or nations share these views, or have the luxury or affluence to indulge these desires. Moreover, we uncritically hold that heritage, specifically "world heritage", must necessarily be a good thing ([40], p. 558). 
Meskell suggests we are "impelled to rethink the more mundane, but no less political, constructions of the past" ([40], p. 570), and the invocations of heritage arising from the narrative of Sud Italia provide a means to do so.

The name of the business, literally "South Italy", and the use in its logo of the crown of the Kingdom the Two Sicilies ${ }^{3}$, signposts and celebrates long-established interpretations of Southern alterity operating within Italian popular consciousness. Recounting the story of a man rising from humble origins as a fruit seller, Silvestro presents his Neapolitan grandfather as an embodiment of the ingenuity and resilience that form part of a collective imaginary of Naples and its inhabitants-as well that of a wider, imagined "Italian South" for which the city and/or its language, often "carry identity functions" ([41], p. 64). Simultaneously defending a holistic vision of Italy-"for me it's all the same, North, South, there's no difference" — and staking a claim in bounded identifications constructed around non-Neapolitan, non-Southern others- "Neapolitan pizza must be made by a Neapolitan. Otherwise...well, I don't think it's impossible, it can be done, but for me...well, that's the secret", Silvestro's discourse exemplifies the argument extended by Abarca: that essentializing claims are derived also from within cultures. As Abarca has shown, bounded identifications of "authentic" culture also work to stifle creativity, and the heritage claims that develop from these essentialized imaginaries of Naples, Naples-as-the-South, and, albeit to a lesser extent, Naples-as-Italy, and their respective "others" (the wider Italian South, the North, and, in this case, London-as-England) can be seen as reflections of such a tension. The relationship between UNESCO and Neapolitan pizza provides a case in point.

Neapolitan Pizza already has TSG (“Traditional Speciality Guaranteed”) EU status, meaning that only specific ingredients and particular cooking methods can be used in pizzas which are declared to be "Neapolitan". Intangible Cultural Heritage status has been applied for both for the pizza, and for the protection it promises for pizzaioli, "pizza-makers", as artisans. The latest (unsuccessful) petition was proposed in 2014 and widely reported in London newspapers [42]. When I asked Silvestro about this petition, he reasoned:

You know that now the Neapolitan language is...it's recognised as a language by UNESCO, so if pizza becomes acknowledged in the same way, I'd be really happy about it. Because, if you think about it, all over Italy, if someone wants to talk about negative things, it's all, where is the mafia, where's the camorra? Naples. Where's all the rubbish? Naples. You know...all the bad things get associated with that city. But if I have to suggest a place in Italy for an English person to visit, when they come here for a bit of pizza, I tell you go to Sicily, I tell you go to Calabria, go to Naples-because it's beautiful.

Invoking an alleged UNESCO recognition of Neapolitan as a language (rather than a local dialect) to assert the value of Neapolitan culture, Silvestro demonstrates the weight of outsider judgement in heritage discourse- a paradigm further supported by the general currency of this statement. The conferral of language status on Neapolitan as well as/or its inscription on the UNESCO Representative List of the Intangible Cultural Heritage of Humanity is widely fêted not only in popular discourse but reported across a variety of print and digital media: "Yet more recognition for the city of Naples: Neapolitan, with its words, is not a dialect but most certainly a language. It is UNESCO to say so, to the point of recognizing it as heritage for the whole of humanity" claimed La Stampa Del Mezzogiorno, to cite but one representative example amongst many [43]. This apparent misreporting probably stems from the fact that a language broadly defined as "South Italian", or "Neapolitan" and recognised as spoken across the South of Italy (from easternmost Umbria to Calabria) is acknowledged by UNESCO as a "vulnerable language", with 7.5 million speakers; in this sense, it is no more or less of a language than dialects spoken in cities across Italy, such as Sassarese [44]. However, Neapolitan is not classified

3 "Il Regno delle Due Sicilie", or "The Kingdom of the Two Sicilies" (1816-1860), of which Naples was the capital, was the largest state of the Italian pensinular prior to Italian unification. 
as UNESCO Intangible Cultural Heritage, nor does its entry as an endangered language correspond to the accordance of language status and consequent protection on the part of the Italian State, as has (somewhat controversially) been granted to Sardinian or Friuilian, or Albanian or Catalan, for example. Leaving aside debate surrounding the relevance or arbitrariness of official language status, the interest here lies in the power and significance afforded to the outsider judgement represented by this imagined institutional recognition. In this paradoxical construct, heritage claims function to bind an element of society together by appealing to the authority of precisely that which is excluded from this commonality. In the concept of heritage employed here, we can consequently trace an extension of the conflict of the traditional self/other construct, whereby the other not only is a necessary threat, a source of anxiety ("I think that the South has always been put down compared to the North") through which a collective identification is formed ("But instead no, we're from the South and look what we're capable of"), but is also a source of authority through which the images and material carrying this sense of collectiveness are ratified, protected and valued:

I think it's the right thing to do, to make pizza the property of UNESCO, because in any way you're going to protect that product and...and make it, and render it, let's say, unique, and make everyone realise the value of Naples even in this.

However, should such legislation be enforced, Silvestro admits that he would be forced to acknowledge that his pizza "isn't actually the real 'authentic Neapolitan pizza'". The process of making the dough that he has developed, he explains, includes the substitution of a small percentage of the white flour with whole-wheat flour, because

it makes it more digestible. It tastes the same-but you don't find it sitting on your stomach hours after [...]. I've studied it over the years-yes, I come from a line of bread makers, but [...]. In a way, I've learned to make pizza in London, I've studied different techniques, and that's the result.

This modification would not meet the requirements stipulated for an "authentic Neapolitan pizza" ("verace pizza napoletana"), which prescribes the exclusive use a specific white flour (farina di grano tenero 00). Silvestro's innovations in the cooking processes, and enthusiastic passion with which he describes the elaboration of the dough "You know, it's like a baby. He needs time to grow properly - then he matures nicely, he's a good person to work with!" marks a creativity that would in effect be excluded from, or "stifled by", as Abarca puts it ([15], p. 3) by the essentializing requirements of UNESCO heritage status. It is difficult to project how the politics-and economics-of this institutional recognition of "value" would be played out in everyday life-whether UNESCO status would work to protect the practice of making pizza against "homogenizing" global forces ([12], p. 155), and bestow prestige upon the local identity with which it is associated, or jeopardize the experimental creativity of artisans like Silvestro.

Returning to Silvestro's personal identification as Neapolitan, we can surmise that this appears to be as much about subscribing to a series of values symbolised by Naples or Neapolitan-ness, "Napoletanità", ("look what we are capable of, look how we do things") as it is an attachment to the aesthetics of the physical city ("it's beautiful"). Embodied knowledge (making pizza), sociality and resourcefulness ("the art of getting by") are defended as "Neapolitan" assets: Naples in this sense corresponds to home as the original source of a perceived shared frame of reference, even though Silvestro has never lived there. "Yes, I was born in Pescara", he concedes, "but all my family are Neapolitan". Upholding his grandfather as an incarnation of Napoletanità and asserting his right to identify as Neapolitan through these family ties, Silvestro's identification recalls the Latin origins and traditional inheritance practices (heres, hered-, "heir") of transmission from parent to child associated with the term heritage. In translating anxieties regarding the present or the future into a veneration of elements of the past, heritage therefore marks generational transfer as a key site of "the creation and contestation of memory and identity politics" ([38], p. 3). Heritage construed in this way-as 
embodied in previous generations of family members and flowing down to descendants-appears to bear particular weight amongst subsequent generations of Italians living outside of Italy. Val, for example, a third generation Italian whose grandfather migrated from Benevento to Italy in the early twentieth century, explained that her grandfather's image represented what she thought of as a "real" Italian. Expressing regret that the Italian heritage of her family had, and would continue to be, in her words, "diluted" over generations, she offered an image of heritage as a sort of essence that can evaporate out of one's grasp if certain language skills, in this case speaking Italian, or somatic contact points—with people, with places—are not maintained.

Resuming our exploration of the theoretical value of heritage, as an analytical conception that can shed light on the interaction between individual meaning-making and public expressions of private affects and anxiety, the various invocations and applications of the term cited above suggest further need for the reconceptualization of heritage, as well as the experience of mobility, from a temporal perspective. As Meskell points out, the type of past invoked in UNESCO global heritage discourse is "a teleological category in our [Western] case, whereas other groups do not perceive our version of the past as past at all" ([40], p. 567). In one sense, the identifications of heritage value presented here point to the valuation of sociality, resourcefulness and embodied knowledge on an individual level that may be located in broader debates of fears of social fragmentation and automation particular to a Western prerogative. Given their currency in Western collective imaginaries we ought to ask how far these assertions of heritage correspond to desires for a more secure "temporal anchoring", as Andreas Huyssen puts it, suggesting that contemporary fascination with the past is due to "an informational and perceptual overload combined with a cultural acceleration that neither our psyche nor our senses are adequately equipped to handle" ([45], p. 25).

It is very evident that asserting both personal and collective heritage involves staking a place in an imagined frame of reference whose sense of commonality rests on the exclusion of others. We need to ask not just who is laying claim to heritage, but from whom is it being sourced, and pay further attention to the dynamics of these articulations. This issue is intrinsic to concept of "universal" heritage value propagated by UNESCO, Harrison argues, in that it "assumes a particular (Western) model of heritage in which the values of an object of place are inherent in its physical fabric" ([12], p. 190). Using heritage to pinpoint and trace the shifts in value that the mobility of people, things-including literal consumables, such as food-and ideas through and across time can being into effect, we can raise questions regarding the processes implicated in intergenerational transfer, and offer new perspectives on the life course as an part of the interpretative framework through which we construct our subjectivity.

\section{Conclusions: On Reading the "Terms" of Mobility through Individual Perspectives}

"Identity is like a bus", asserts Stuart Hall:

not because it takes you to a fixed destination, but because you can only get somewhere-anywhere-by climbing aboard. The whole of you can never be represented by the ticket you carry, but you will still have to buy a ticket to get from here to there ([46], p. 65).

This article uses not a bus, but the narratives arising from Citroën $\mathrm{H}$ van of Sud Italia to reflect upon the concepts of belonging, home, and heritage as relevant to one "identity in motion". In parallel with Hall's depiction of identity, analysis of the narrative of Sud Italia reveals a contradictory nexus of movement and fixity in which greater economic mobility is attained in part through being objectified or "fixed" as "Italian". Yet mobility has been shown to be implicit even in the "fixing" of subjects-as-objects: being "read" as Italian depends on transnational movement, and Sud Italia in this sense can be interpreted as a "transnational object", brought into being by mobility between cultures and nations. Here, this process of mobility has been defined as "belonging"; as being "rightly placed in a specified position", and emphasis is placed on the distinction between this construal of 
belonging, and a sense of home. The idea of home constructed in this analysis relates to the ability to interpret individual emplacement and experience through a collective frame of reference (in itself fluid and heterogeneous, shifting over time in relation to environmental, temporal and social context), and consequently the possibility of belonging and feeling at home in quite different geographical situations has been further confirmed from an alternative perspective.

What are the practical implications of the shift between home and belonging, and the new frames of reference that can arise as part of the experience of mobility? In posing this question, I have emphasized the need to interrelate individual accounts of mobility to wider social patterns and development. Regarding Italian migration, much has been gained from the increasing attention paid to the "private" lives of specific individuals in particular circumstances as the site in which ideas of the "nation" are constructed [11], as well as the broader socio-historical evaluations cited previously [1]. This article argues for the necessity of developing perspectives which are informed explicitly by both these approaches to explore more fully how personal experience is not only informed by, but works to inform social trends, specifically in relation to Italy. How does mobility-in the form of both immigration and emigration - shape not only the lives of individuals, but reshape and structure that which is defined as "Italy" in various collective imaginaries - those of migrant Italians, and that of the nation-state of Italy?

The concept of heritage emerges through the narrative of Sud Italia as a key intersect between private affect and public articulation. Contradictions are implicit in the term, which appeals to institutional authorities, such as UNESCO, for the valorization and reification of apparently intensely personal values and practices; making pizza, or speaking a local language. These tensions are reflected in the pertinence it acquires in individual expression. Heritage is on the one hand an imprecise resource that is seen as embodied in family members and transmitted as an indefinite set of values, affects and practices, to which subscription marks out the boundaries of a collective. On the other, through the concept of "global heritage", specific perspectives-predominantly Western-transform reservations regarding the present and/or future into a celebration of the past, bestowing significance upon certain practices and artefacts. Heritage therefore represents both personal explorations of meaning and the articulation of group affect and anxiety, and implicates both in hierarchies of power and authority. Further critical attention to the concept promises not only alternative ways of conceptualizing the life course and intergenerational transfer, but also new insights into the mobility of people, ideas, and things through and across time, and the changes in value these processes generate.

Acknowledgments: The fieldwork on which this article is based is carried out as part of the "Transnationalizing Modern Languages" project, funded by the Arts and Humanities Research Council under its "Translating Cultures" theme. I would like to thank Silvestro Morlando, the pizzaioli of Sud Italia, Aldo Carola, and the participants who remain anonymous for their availability and collaboration. I am also particularly grateful to Jennifer Burns for her invaluable comments and suggestions for revision, as well as two anonymous reviewers for their thoughtful engagement with the manuscript.

Conflicts of Interest: The author declares no conflict of interest. The funding sponsors had no role in the design of the study; in the collection, analyses, or interpretation of data; in the writing of the manuscript, and in the decision to publish the results.

\section{Abbreviations}

TML Transnationalizing Modern Languages

UNESCO United Nations Educational, Scientific and Cultural Organization

\section{References and Notes}

1. Terri Colpi. The Italian Factor. Edinburgh: Mainstream Publishing, 1991.

2. Carole M. Counihan, and Penny Van Esteric, eds. Food and Culture: A Reader, 3rd ed. Oxford and New York: Routledge, 2013.

3. Judy Attfield. Wild Things: The Material Cultures of Everyday Life. Oxford: Berg, 2000. 
4. Carole M. Counihan. The Anthropology of Food and Body: Gender, Meaning, and Power. Hove: Psychology Press, 1999.

5. Jay Allan Anderson. Scholarship on Contemporary American Folk Foodways. Copenhagen: Ethnologia Europaea, 1971, pp. 56-63.

6. Arthur Lizie. "Food and communication." In Routledge International Handbook of Food Studies. Edited by Ken Albala. London and New York: Routledge, 2013.

7. Transnationlizing Modern Languages. "Transnationlizing Modern Languages: Mobility, Identity and Translation in Modern Italian Cultures." Detailed project outline (including references to public policy statements and reports). Available online: http://www.transnationalmodernlanguages.ac.uk/about/project/ (accessed on 9 February 2016).

8. Deborah Lupton. Food, Body and the Self. London: Sage Publications, 1996.

9. Giuseppe Scotto. "From 'emigrants' to 'Italians': What is new in Italian migration to London? " Modern Italy 20 (2015): 153-66. [CrossRef]

10. Ditty Dokter, and Margaret Hills de Zarate. Intercultural Research in Arts Therapies. Oxford: Routledge, 2016, forthcoming.

11. Loretta Baldassar. “Obligation to People and Place. The National in Cultures of Caregiving." In Intimacy and Italian Migration: Gender and Domestic Lives in a Mobile World. Edited by Donna R. Gabaccia and Loretta Baldassar. New York: Fordham University Press, 2010, pp. 171-87.

12. Rodney Harrison. "The Politics of Heritage." In Understanding the Politics of Heritage. Edited by Rodney Harrison. Manchester: Manchester University Press, 2010, pp. 154-96.

13. Abel Duarte Alonso. "'Tannat' the positioning of a wine grape as symbol and 'referent' of a nation's gastronomic heritage." Journal of Heritage Tourism 8 (2013): 105-19. [CrossRef]

14. Anne Allison. "Japanese Mothers and Obentos: The Lunch-Box as Ideological State Apparatus." In Food and Culture: A Reader, 3rd ed. Edited by Carole M. Counihan and Penny Van Esteric. Oxford and New York: Routledge, 2013, pp. 154-72.

15. Meredith E. Abarca. "Authentic or Not, It's Original." Food and Foodways 12 (2004): 1-25. [CrossRef]

16. Donna R. Gabaccia, and Loretta Baldassar. Intimacy and Italian Migration: Gender and Domestic Lives in a Mobile World. New York: Fordham University Press, 2010.

17. Ian Cook, and Philip Crang. "The World on a Plate: Culinary Culture, Displacement and Geographical Knowledges." Journal of Material Culture 1 (1996): 131-53. [CrossRef]

18. TimeOut London. "Spitalfields Market." 30 November 1999. Available online: http:/ /www.timeout.com/ london/shopping/spitalfields-market (accessed on 14 April 2016).

19. Katie Dailey. “Spitalfields Market: An insider's guide." TimeOut London, 16 January 2015. Available online: http:/ / www.timeout.com/london/shopping/spitalfields-market-guide (accessed on 14 April 2016).

20. The area is a part of a larger local governement ward which was established in 1998, "Spitalfields and Banglatown". In formally recognising the significance and impact of Bangladeshi and British-Bangladeshi culture in the area, this name came under attack from local Conservatives, who lobbied unsuccessfully for "Banglatown" to be removed. Census data identified that $58 \%$ of the population in Tower Hamlets (the borough of which Spitalfields and Banglatown forms part) belonged to an ethnic group other than White British. 33\% of the population were Bangladeshi, 7\% came from African/Caribbean backgrounds and the total White British population was $42 \%$. Wayback Machine. "Tower Hamlets Borough Statistics." Available online: http://web.archive.org/web/20080415000301/http://www.towerhamlets.gov.uk/data/ discover/data/borough-profile/index.cfm (accessed on 25 January 2016).

21. Arjun Appdurai. “On Culinary Authenticity." Anthropology Today 2 (1986): 24-25.

22. Tammi Jonas. "Eating the Vernacular, Being Cosmopolitan." Cultural Studies Review 19 (2013): 117-37. [CrossRef]

23. Abraham Maslow. "A Theory of Human Motivation." Psychological Review 50 (1943): 370-96. [CrossRef]

24. David W. McMillan, and David M. Chavis. "Psychological Sense of Community: A definition and theory." American Journal of Comunity Psychology 14 (1986): 6-23.

25. Judith Butler. Gender Trouble: Feminism and the Suberversion of Identity. New York: Routledge, 1990.

26. Tim Edensor. National Identity, Popular Culture and Everyday Life. Oxford: Berg, 2002.

27. Terry Lovell. "Thinking feminism with and against Bourdieu." In Reading Bourdieu on Society and Culture. Edited by Bridget Fowler. Oxford: Blackwell Publishers, 2000, pp. 27-48. 
28. Laura U. Marks. The Skin of the Film: Intercultural Cinema, Embodiment, and the Senses. Durham and London: Duke University Press, 2000.

29. Paul Jones, and Michal Kryzyzanowski. "Identity, Belonging and Migration: Beyond Constructing 'Others'." In Identity, Belonging and Migration. Edited by Gerard Delanty, Ruth Wodak and Paul Jones. Liverpool: Liverpool University Press, 2008, pp. 38-53.

30. Erving Goffman. Forms of Talk. Pennsylvania: University of Pennsylvania Press, 1981.

31. David Morley. Home Territories: Media, Mobility and Identity. London and New York: Routledge, 2000.

32. Jennifer Burns. "Home." In Migrant Imaginaries: Figures in Italian Migration Literature. Bern: Peter Lang, 2013, pp. 101-30.

33. Ambasciata Italiana Londra. Appunto: La Comunità Italiana in Gran Bretagna. London: Ambasciata Italiana Londra, 2006.

34. Russell King, Aija Lulle, Francesca Conti, Dorothea Mueller, and Giuseppe Scotto. “The lure of London: A comparative study of recent graduate migration from Germany, Italy and Latvia." SCMR Working Paper, 2014. Available online: https:/ /www.sussex.ac.uk/webteam/gateway / file.php?name=mwp75.pdf\&site=252 (accessed on 15 February 2016).

35. Bo Stråth. "Belonging and European Identity." In Identity, Belonging and Migration. Edited by Gerard Delanty, Ruth Wodak and Paul Jones. Liverpool: Liverpool University Press, 2008, pp. 21-37.

36. Michel de Certeau. The Practice of Everyday Life. Translated by Steven Rendall. Berkeley: University of California Press, 1984.

37. Graeme Davidson. "Heritage: From Patrimony to Pastiche." In The Heritage Reader. Edited by Graham Fairclough, Rodney Harrison, John Schofield and John H. Jameson. Oxford: Routledge, 2008, pp. 31-40.

38. Rodney Harrison, Graham Fairclough, John H. Jameson, and John Schofield. "Introduction: Heritage, Memory and Modernity." In The Heritage Reader. Edited by Graham Fairclough, Rodney Harrison, John Schofield and John H. Jameson. Oxford: Routledge, 2008, pp. 1-12.

39. UNESCO. "Mediterranean diet, Lists of Intangible Heritage." Available online: http:/ /www.unesco.org/ culture/ich/index.php?lg=en\&pg=00011\&RL=00884 (accessed on 10 February 2016).

40. Lynn Meskell. "Negative Heritage and Past Mastering in Archaeology." Anthropological Quarterly 75 (2002): 557-74. [CrossRef]

41. Richard J. Blackwood, and Stefania Tufi. The Linguistic Landscape of the Mediterranean: French and Italian Coastal Cities. London: Palgrave Macmillan, 2015.

42. See for example Lizzie Edmonds. "London chefs unite in bid to make Neapolitan pizza recipe a world cultural treasure." Evening Standard, 13 November 2014. Available online: http:/ /www.standard. co.uk/news/london/london-chefs-unite-in-bid-to-make-neapolitan-pizza-recipe-a-world-cultural-treasure9858046.html (accessed on 31 January 2016).

43. "E" arrivato un altro riconoscimento per la città di Napoli: Il napoletano, con le sue parole, non è "un dialetto ma bensì una lingua. A dirlo è l'UNESCO, tanto da riconoscerlo come patrimonio per l'intera umanità" (Yet more recognition for the city of Naples: Neapolitan, with its words, is not "a dialect but most certainly a language. It is UNESCO to say so, to the point of recognising it as heritage for the whole of humanity"), cited in Rosalia Gigliano. "Il dialetto napoletano diventa patrimonio dell'UNESCO: È la seconda lingua d'Italia." La Stampa Del Mezzogiorno, 24 January 2014. Available online: http://www.lastampadelmezzogiorno.it/napoli/11436-il-dialetto-napoletano-diventa-patrimoniodell'unesco-è-la-seconda-lingua-d'italia.html (accessed on 31 January 2016).

44. Entry for "South Italian." UNESCO Interactive Atlas of the World's Languages in Danger. Available online: http:/ / www.unesco.org/languages-atlas/index.php (accessed on 31 January 2016).

45. Andreas Huyssen. Present Pasts: Urban Palimpsests and the Politics of Memory. Stanford: Stanford University Press, 2003.

46. Stuart Hall. "Fantasy, Identity, Politics." In Cultural Remix: Theories of Politics and the Popular. Edited by Erica Carter, James Donald and Judith Squires. London: Lawrence and Wishart, 1995, pp. 63-71.

(c) 2016 by the author; licensee MDPI, Basel, Switzerland. This article is an open access article distributed under the terms and conditions of the Creative Commons Attribution (CC-BY) license (http://creativecommons.org/licenses/by/4.0/). 